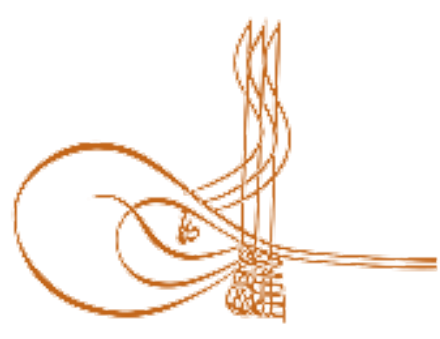

www.turkishstudies.net/education
Turkish Studies - Educational Sciences

eISSN: 2667-5609

Research Article / Araștırma Makalesi

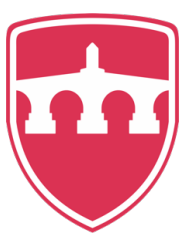

INTERNATIONAL BALKAN

UNIVERSITY

Sponsored by IBU

\title{
Beden Eğitimi ve Spor Öğretmenleri ile Diğer Öğretmenlerin Sosyal Görünüş Kaygısı ve Saldırganlık Tutumlarının İncelenmesi
}

\author{
Investigation of Social Appearance Anxiety and Aggressive Attitudes of Physical Education and \\ Sports Teachers and Other Teachers
}

\author{
Metin Karayol $^{*}$ - Mehmet Demirel ${ }^{* *}$
}

\begin{abstract}
In this study, it is aimed to investigate the aggressive attitudes and social appearance anxiety of physical education and sports teachers and other teachers. The study consists of physical education and sports teachers and other teachers teaching in Eastern and South Eastern Anatolia regions $(n=372)$. The personal information form has been used to identify the demographic features of the participants by the researchers. "Social Appearance Anxiety Scale", whose Turkish edition has been conducted by Doğan (2010) and developed by Hart at al. (2008) to identify the social appearance anxiety of the participants and "Aggressiveness Scale" developed by Tuzgöl (1998) has been used to measure the aggressive attitudes by benefiting "Aggressiveness Inventory" by Kocatürk (1982). Number, percentage, average, standard deviation has been used as descriptive statistical methods in the evaluation of datum. According to the normality test in data analysis, T-Test has been used in pairwise comparisons and ANOVA test has been used to identify the difference between more than two dependent and independent variables. T-test has been used in comparison of quantitative continuous data between two independent groups. Pearson Correlation Analysis has been conducted between the continuous variables of the study. The datum obtained in the study has been analyzed by using SPSS 22.0 program. As a consequence: It has been seen that there is a significant difference in terms of age, teaching experience and their administrative functions variables in social appearance anxiety of physical education and sports teachers and aggressiveness inventory scales $(p<0,05)$. However, it has been seen that there is no significant difference in terms of gender, marital status and the school they're working $(p>0,05)$. It has been seen that there is a significant difference in terms of gender and the school they're working for other branches of teachers $(p<0,05)$. It has been identified that aggressive points of physical education and sports teachers are higher than the other teacher. In addition to that, it has been found out that there is a significant difference in a positive way between social appearance anxiety and aggressive attitudes.
\end{abstract}

\footnotetext{
${ }^{*}$ Dr. Öğr. Üyesi, Muş Alparslan Üniversitesi, Beden Eğitimi ve Spor Yüksekokulu, Spor Yöneticiliği Bölümü

Asst. Prof. Dr., Mus Alparslan University, High School of Physical Educaiton and Sport, Department of Sport Management

ORCID 0000-0003-0809-0410

m.karayol@alparslan.edu.tr

** Doç. Dr., Necmettin Erbakan Üniversitesi, Turizm Fakültesi, Rekreasyon Yönetimi Bölümü

Assoc. Prof. Dr., Necmettin Erbakan University, Faculty of Tourism, Department of Recreation Management

ORCID 0000-0003-1454-022X

mehmetdemirel78@gmail.com

Cite as/ Atıf: Karayol, M. (2020). Beden eğitimi ve spor öğretmenleri ile diğer öğretmenlerin sosyal görünüş kaygisi ve saldirganlik tutumlarinin incelenmesi, Turkish Studies - Education, 15(2), 1011-1023. https://dx.doi.org/10.29228/TurkishStudies.40467

Received/Geliş: 08 January/Ocak 2020

Accepted/Kabul: 28April/Nisan 2020

Copyright $\mathbb{C}$ INTAC LTD, Turkey

Checked by plagiarism software

Published/Yayın: 30 April/Nisan 2020

CC BY-NC 4.0
} 
By considering those results, enhancing the seminars in teaching programmes and educational programmes in terms of improving current situation and designing different programmes have been suggested.

Structured Abstract: Introduction As it is well-known, many students draw attention in dynamic structure of young population potential of our country. In this context, it causes teachers teaching both in primary and secondary schools to have a mission as being a role model for always young and dynamic students.

Education must have all the superior qualifications and equipment to be successful. Education has many elements. Teachers are the most important ones of these elements. Teachers are first degree responsible for the education of the students in the classroom. Teaching as a job in Turkey has to be conducted by more equipped ones after the effect of positive developments in global world and countries (Taşkaya, 2012). Thus, social appearance anxiety of teachers can be evaluated in terms of their colleagues, students and status in society. Social appearance anxiety can trigger aggressive conditions according to their inner world and present point of view and each individual cannot be in the same threshold in terms of anger control.

Of course, it is possible to say the branch differences in the conditions such as physiologic and psychological field dominance related to their branches of each teacher. One of these differences between individual is the rule of dress which is the window of human in social life. Also, when the definitions which researches related to social appearance anxiety about individuals' physical structure and dressing styles made were investigated (Çınar and Keskin, 2015; Kara, 2016), social appearance anxiety is the sentimental reaction that individuals feel toward anxiety condition and evaluations exhibited while their physical conditions are analyzed by other individuals. Social appearance anxiety because of individual's physical appearance is explained as the fear of negative evaluation (Hart and others, 2008).

According to Tiryaki (1997), aggressiveness "is a multifaceted concept that needs to evaluated with aim, intention, sentiment and attitude elements." Therefore, it is hard and complicated to define aggressiveness peremptorily exact. When looking up the literature, that there are many definitions of aggressiveness is because it is hard and complicated. According to a different definition, aggressiveness "is a kind of behavior that is an effort to predominate others, to control; poison the well on, battering, offending and agonizing/hurting" (Tiryaki, 2000).

If we need to deduce from these definitions, we can notice that there is a physical interference. Apart from that, if it is necessary to speak of verbal and sentimental aggressiveness, sentimental aggressiveness "when it has aims that are letting individuals sentimentally down, depressing and leading to trouble, weakening their motivations, making them lose self-confidence, verbal aggressiveness has aim to damage, insult and offend individuals" (Doğan, 2005).

Sports have importance in terms of providing individuals to have sense of belonging to the society and fit into society (Eroğlu and Acet, 2017; Gümüşay, 2019; Murathan ve Murathan, 2019). It is important to investigate the social appearance anxiety and aggressive attitudes of physical education and sports teachers and other teachers as a part of the society.

\section{Purpose of the Research}

It has been aimed to investigate social appearance anxiety and aggressive attitudes of physical education and sports teachers and other teachers.

\section{Method}

Population of this research consists of the teachers participating voluntarily, teaching in Eastern Anatolia and Southeastern Anatolia with sample survey method. Sample group consists of 372 teachers in total teaching at primary schools with a number of 203 and secondary schools with a number of 169 . While 156 physical education and sports teachers are in the research, there are 124 primary and 92 secondary school teachers teaching at different branches.

The distribution by provinces of teachers participated in the study has been reported as Erzurum (27), Muş (63), Van (60), Batman (58), Elazı̆g (51), Bitlis (54) ve Bingöl (59) and 372 in total. 
Beden Eğitimi ve Spor Öğretmenleri ile Diğer Öğretmenlerin Sosyal Görünüş Kaygisi ve.... 1013

\section{Data Collection Tools}

\section{Social Appearance Anxiety Scale}

Turkish transcription of the scale developed to measure social appearance anxiety of the individuals by Hart. and his friend has been made by Doğan (2010) The scale consists of 16 articles.

\section{Aggressiveness Inventory}

Aggressiveness scale developed from Kocatürk (1982) by Tuzgöl (1998) consists of 45 articles. In the scale, there are 30 aggressive thematic and 15 nonaggressive articles. Nonaggressive articles are such as: $2,4,8,10,13,16,24,28,33,35,37,38,39,40,44$ and other articles are represented as aggressive thematic articles.

\section{Conclusion and Suggestions}

Aggressiveness points have shown significant difference in terms of the branches of teachers $(t(370)=3.132 ; p=0.002<0,05)$. Aggressiveness points of physical education and sports teachers $(\bar{x}=92,410)$, have been found out higher than other branches of teachers $(\bar{x}=88,148)$. It has been thought that this situation is because physical education and sports teachers interact with their students not only in the classroom but also in their free times at school and consequently physical education and sports teachers can be impatient when behaving their students because the students are abusing this interaction.

When correlation analysis was examined, $\mathrm{r}=0.413$ positive relation has been found out between social appearance anxiety and aggressiveness $(\mathrm{p}=0,000<0.05)$.

The points of social appearance anxiety and aggressiveness in physical education and sports teachers according to the gender variable has shown significant difference $(\mathrm{p}>0.05)$. The social appearance anxiety points of the participants $(\overline{\mathrm{x}}=32,295)$ aged 30 and under has been found higher than the social appearance anxiety points of the ones over $30(\overline{\mathrm{x}}=28,423)(\mathrm{t}=2,067 ; \mathrm{p}=0.041<0.05)$. In the study performed by Telli and Ünal (2016) paralleled to our study, when looking up to social appearance anxiety in terms of the university students' socio-demographic structures, a significant difference has been found out between the social appearance anxiety of the university students and their class grade.

From this point, we can say that social appearance anxiety decreases paralleled to the age as the age increases. The points of social appearance anxiety and aggressiveness has shown a significant difference according to the school variable $(\mathrm{p}>0.05)$. Aggressiveness points have indicated a significant difference according to the teaching experience variable $(\mathrm{F}=3,178 ; \mathrm{p}=0.026<0.05)$. The reason of the difference is that the points of the ones whose teaching experiences are less than 2 years are higher than the ones whose teaching experiences are 3 and 5 years $(p<0.05)$. The aggressiveness points of the ones whose teaching experiences are less than 2 years are higher than the ones whose teaching experiences are 6-10 years $(\mathrm{p}<0.05)$. The aggressiveness points of the ones whose teaching experiences are less than 2 years are higher than the ones whose teaching experiences are 10 years and over $(p<0.05)$. Social appearance anxiety points have shown a significant difference according to the teaching experience $(p>0.05)$. This situation can be explained that teachers along with the age decrease their aggressive attitudes in a positive way. All in all, the fact that physical education and sports teachers sports backgrounds, sportive organizations that they participated and their interactions with sportsmen and individuals from different cultures along with various activities and feeling of self-confidence much more in daily life that they gained from sports can be shown as the reason of getting low points when their social anxiety levels are compared to demographic information. It has been identified that social appearance anxiety points of the ones who have administrative duties $(\overline{\mathrm{x}}=36,000)$ are higher than the ones who do not $(\overline{\mathrm{x}}=29,669),(\mathrm{t}=2,108 ; \mathrm{p}=0.037<0.05)$. Aggressiveness points have shown a significant difference according to administrative condition $(\mathrm{p}>0.05)$. It can be said that with clothing style peculiar to their continuous occupation, physical education and sports teachers behave neatly when they have an administrative duty. It has been stated that in other branches of teachers, aggressiveness points of the females $(\overline{\mathrm{x}}=85,947)$, are lower than the aggressiveness points of the male $(\overline{\mathrm{x}}=90,608)$ ones $(\mathrm{t}=-$ 2,$828 ; \mathrm{p}=0.005<0.05$ ). In the study conducted by Eroğlu (2009), it shows parallelism with our study that male students have got more aggressive points than female ones in most of the sub dimensions. Social appearance anxiety points have shown a significant difference according to gender variable $(\mathrm{p}>0.05)$. Social appearance anxiety and aggressiveness points have shown a significant difference according to age variable $(\mathrm{p}>0.05)$.Social appearance anxiety and aggressiveness points have shown a significant difference according 
to marital status variable ( $\mathrm{p}>0.05$ ). It has been found out that social appearance points of the ones who are teaching at Primary Schools $(\overline{\mathrm{x}}=29,476)$ are higher than the ones teaching at high $\operatorname{schools}(\overline{\mathrm{x}}=32,707),(\mathrm{t}=-$ $2,333 ; p=0.027<0.05)$. In the study conducted by Alemdağ and Öncü (2015) and also paralleled to our study, it has been determined that first and second grade students at university have higher points in social appearance anxiety than the ones who are studying at third and fourth grade. This situation can be thought that the teachers give importance to their social appearances more carefully without avoiding the fact that high school students take their teachers as role models because they reach puberty. The aggressiveness points of the teachers have shown a significant difference according to the school variable $(\mathrm{p}>0.05)$. The points of social appearance anxiety and aggressiveness have shown a significant difference according to teaching experience variable $(\mathrm{p}>0.05)$. The points of social appearance anxiety and aggressiveness have shown a significant difference according to their administrative duties $(\mathrm{p}>0.05)$.

Keywords: Sports Management, Physical Education and Sports, Anxiety, Attitude, Aggressiveness.

Öz: Bu çalışmada beden eğitimi ve spor öğretmenleri ile diğer öğretmenlerin sosyal görünüş kaygısı ve saldırganlık tutumlarının incelenmesi amaçlanmıştır. Çalışmaya Doğu Anadolu ve Güneydoğu Anadolu'da görev yapan beden eğitimi ve spor öğretmenleri ve diğer öğretmenler oluşturmaktadır ( $n=372)$. Katılımcıların demografik özelliklerini tespit etmek için araştırmacılar tarafından oluşturulan kişisel bilgi formu kullanılmıştır. Katılımcıların sosyal görünüş kaygısını tespit etmek için Hart ve ark. (2008) tarafından geliştirilmiş ve ölçeğin Türkçe uyarlaması Doğan (2010) tarafindan yapılan ' Sosyal Görünüş Kaygısı1 Ölçeği', (SGKÖ), saldırganlık tutumlarını ölçmek için Kocatürk'ün (1982) 'Saldırganlık Envanterinden' yararlanılarak Tuzgöl (1998) tarafından geliştirilen "Saldırganlık Ölçeği” kullanılmıştır. Verilerin değerlendirilmesinde tanımlayıcı istatistiksel yöntemleri olarak sayı, yüzde, ortalama, standart sapma uygulanmıştır. Yapılan normallik testine göre verilerin analizinde, iki gurubun ortalamaları arasındaki farkın anlamlı olup olmadığını incelemek için T-Testi, ikiden fazla bağımsız değişkenler ile bağımlı değişkenler ortalamaları arasındaki farkın tespiti için ANOVA testi kullanılmıştır. İki bağımsız grup arasında niceliksel sürekli verilerin karşılaştırılmasında t-testi, sürekli değişkenleri arasında ise pearson korelasyon uygulanmıştır. Araştırmada elde edilen veriler SPSS 22.0 programı kullanılarak analiz edilmiştir. Sonuç olarak: Beden eğitimi ve spor öğretmenlerinin sosyal görünüş kaygısı ve saldırganlık envanteri ölçeğinde yaş, öğretmenlik tecrübesi ve idari görev durumu değişkenlerine göre anlamlı farklılık görülmüştür $(p<0,05)$. Ancak cinsiyet, medeni durum ve çalışılan okul değişkenlerine göre anlamlı farklılık görülmemiştir $(\mathrm{p}>0,05)$. Diğer branş öğretmenlerin ise cinsiyet ve çalışılan okul değişkenlerine göre anlamlı farklılık görülmüştür $(\mathrm{p}<0,05)$. Ancak yaş, medeni durum, öğretmenlik tecrübesi ve idari görev durumu değişkenlerine göre anlamlı farklılık görülmemiştir ( $\mathrm{p}>0,05)$. Beden eğitimi ve spor öğretmenlerinin saldırganlık puanları diğer branş öğretmenlerinin saldırganlık puanlarından yüksek bulunmuştur. Ayrıca sosyal görünüş kaygısı ve saldırganlık tutumu arasında pozitif yönde anlamlı ilişki bulunmuştur. Bu sonuçlar dikkate alınarak, öğretmenlik programlarında mevcut durumun iyileştirilmesine yönelik seminerler ve eğitim programlarının artırılması ve farklı programların tasarlanması önerilmektedir.

Anahtar Kelimeler: Spor Yönetimi, Beden Eğitimi ve Spor, Kaygı, Tutum, Saldırganlık.

\section{Giriş}

Bilindiği üzere ülkemizin genç nüfus potansiyelinin dinamik yapısı haliyle eğitim öğretimde okuyan birçok öğrenci dikkat çekmektedir. Bu bağlamda gerek ilköğretimde gerekse ortaöğretimde eğitim öğretim veren öğretmenler her zaman için genç ve dinamik yapıdaki öğrencilere karşı rol model olma noktasında farklı bir misyon üstlenmesine sebep olmaktadır.

Holland'a (1997) kişiler mesleklerini seçerken kişiliklerinin yansıttığı meslek gruplarına yönelmektedir. $\mathrm{Bu}$ düşünceden yola çıkarsak günümüzde mesleki durumun bireylerde kişilik faktörü, cinsiyet durumları ve toplum içerisinde üstlenmiş olduğu faktörlerle ilişkili olduğunu ifade edilebilir.

Eğitimin başarılı olabilmesi için eğitimin bütün yönlerinin üstün niteliklere ve donanımlara sahip olması gerekmektedir. Eğitimin birçok yönü vardır. Bu yönlerden en önemli olanı da 
öğretmenlerdir. Öğretmenler sinıfta bulunan öğrencilerin eğitiminden ilk dereceden sorumlu kişilerdir. Türkiye'de öğretmenlik mesleği, küresel dünyada ve ülkelerde yaşanan pozitif gelişmelerin de etkisiyle artık daha donanımlı kişilerce yapılmasının gerekliliği ortaya çıkmıştır (Taşkaya, 2012). Böylelikle öğretmenlerin sosyal görünüş kaygıları iş arkadaşlarına, öğrencilere ve toplum içerisindeki statülerine göre değerlendirilebilmektedir. Sosyal görünüş kaygısı da mevcut bakış açıları ve kendi içsel düşünce dünyasına göre saldırganlık durumlarını tetikleyebilmekte ve öfke kontrolü noktasında her birey aynı eşikte kalamamaktadır.

Elbette her öğretmenin kendi alanları ile ilgili fizyolojik, psikolojik alana hâkimiyet vs. gibi durumlarda branş farklılıklarından söz etmek mümkündür. Kişiler arası bu farklılıklardan biride kişilerin sosyal yaşam içerisindeki insanın vitrini olan kılık kıyafet ahlaki kurallardır. Ayrıca kişilerin fiziksel yapıları ve kılık kıyafetleri karşıda Sosyal görünüş kaygısı ile ilgili araştırmaların yaptığ1 tanımlar incelendiğinde (Çınar ve Keskin, 2015; Kara, 2016), sosyal görünüş kaygısı, bireylerin fiziksel durum hallerinin diğer bireyler tarafindan analiz edilirken ortaya konan kayg1 durumu ve değerlendirilmelerine karşı hissettikleri duygusal tepkidir. Sosyal görünüş kaygısı, bireyin fiziksel görüntüsünden dolayı negatif şekilde değerlendirileceği korkusu olarak açıklanmaktadır (Hart ve diğ., 2008).

Farklı bir açıdan sosyal görünüş kaygısı ise; kişilerin kilo, boy, ten rengi, kas yapısı gibi özelliklerinin dışında göz biçimi, burun yapısı, gülüş tarzı gibi özellikleri de kapsayan, kişilerin fiziksel görünüşlerinin diğer kişiler tarafından değerlendirilirken yaşadıkları gerginlik ve kaygı olarak açıklanmaktadır (Hart ve diğ., 2008). Sosyal görünüş kaygısı, fiziksel durumun ötesinde daha detayl1 ve bütünsel bir durum da söz konusudur (Doğan, 2010).

Tiryaki' ye (1997) göre saldırganlık "amaç, niyet, duygu ve davranış öğeleri ile birlikte değerlendirilmesi gereken çok yönlü bir kavramdır." Bu sebeple tartışmaya yer vermeyecek kadar net şekilde saldırganlığı tanımlamak oldukça zor ve karışıktır. Literatür bakıldığında saldırganlıkla ilgili birçok tanımının yapılması zor ve karmaşık halinden kaynaklanmaktadır. Farklı bir tanıma göre ise saldırganlık; "karşısındakine üstün gelme çabası, onu yönetmeye çalışmak; bir işin akışını bozmak, hırpalayıcı, incitici acı/ağrı verici davranış biçimidir" (Tiryaki, 2000).

Bu tanımlamalardan ortak bir çakarım yapmak gerekirse fiziksel müdahalenin olduğundan söz edebiliriz. Bunun dışında sözel ve duygusal saldırganlıktan da söz etmek gerekirse, duygusal saldırganlık; "kişileri duygusal olarak çöküntüye uğratan, sıkıntı ve strese sokan, ruhsal yönden motivasyonu düşüren, güvenini kaybettiren amaçlar içerirken, sözel saldırganlık kişilere zarar vermek, aşağılamak ve incitmek gibi amaçlar taşımaktadır” (Doğan, 2005).

Spor, kişilerin toplum içinde uyum sağlaması ve aidiyet duygusunu yaşaması açısından önemli bir noktadadır (Eroğlu ve Acet, 2017; Gümüşay, 2019; Murathan ve Murathan, 2019). Bu gerekçe ile beden eğitimi ve spor öğretmenleri ile diğer öğretmenlerin sosyal görünüş kaygısı ve saldırganlık tutumlarının incelenerek bu kapsamda aşağıdaki alt problemlere cevap aranmıştır. 1 . Öğretmenlerin öğretmenlik alanına göre sosyal görünüş kaygısı ve saldırganlık düzeyleri arasında anlamlı farklılık var mıdır? 2. Öğretmenlerin sosyal görünüş kaygısı ve saldırganlık düzeyleri arasında ilişki var mıdır? 3. Öğretmenlerin sosyal görünüş kaygısı puanlarının tanımlayıcı özelliklerine göre anlamlı farklılık var mıdır? 4. Öğretmenlerin saldırganlık düzeyi puanlarının tanımlayıcı özelliklere göre anlamlı farklılık var mıdır?

\section{Yöntem}

$\mathrm{Bu}$ araştırmanın evrenini Doğu Anadolu ve Güney Doğu Anadolu'da öğretmenlik yapan gönüllülük esasına göre katılan öğretmenlerden oluşmaktadır. Örneklem grubu ise ilköğretim eğitim veren (203) ve ortaöğretimde eğitim veren (169) toplamda 372 öğretmenden oluşmaktadır. Araştırmada 156 beden eğitimi ve spor öğretmeni yer alırken farklı branşlarda eğitim veren 124 ilköğretim ve 92 ortaöğretim öğretmeni yer almaktadır. 
Araştırmaya katılan öğretmenlerin illere göre dağılımı ise Erzurum (27), Muş (63), Van (60), Batman (58), Elazığ (51), Bitlis (54) ve Bingöl (59) toplamda 372 olarak tespit edilmiştir.

\section{Sosyal Görünüş Kaygısı Ölçeği (SGKÖ)}

Hart ve ark. (2008) Tarafından kișilerin sosyal görünüş kaygılarını ölçmek amacıyla geliştirilen ölçeğin Türkçe uyarlaması Doğan (2010) tarafından yapılmıştır. 5' li likert tipi olan bu ölçek 16 maddeden oluşmaktadır. Tek boyutlu olan ölçekte en düşük puan 16 ve en yüksek puan 80'dir. Puanın yükselmesi sosyal görünüş kaygısının yüksek olduğuna işaret etmektedir. Bu araştırmada Sosyal Görünüş Kaygısı ölçeğinin güvenirliği Cronbach's Alpha=0,926 olarak yüksek bulunmuştur.

\section{Saldırganlık Envanteri}

Araştırmada Kocatürk'ün (1982) 'Saldırganlık Envanterinden' yararlanılarak Tuzgöl (1998) tarafından geliştirilen "Saldırganlık Ölçeği”" uygulanmıştır. 45 maddeden oluşan ölçekte 30 saldırgan içerikli, 15 saldırganlık içermeyen madde vardır. Ölçekteki saldırganlık içermeyen maddeler şunlardır: $2,4,8,10,13,16,24,28,33,35,37,38,39,40,44$, diğer maddeler saldırgan içerikli davranışları ifade eden maddelerdir. Ölçek içerisinde ters sorulara verilen cevaplar yeniden kodlanarak toplam puan elde edilmiştir. Tüm maddelere verilen cevapların toplamı kişinin saldırganlık puanını oluşturmaktadır. Çalışılan örneklemin aritmetik ortalamasının üstündeki puanlar yüksek saldırganlık düzeyini, altındaki puanlar düşük saldırganlık düzeyini temsil etmektedir. Ölçekten alınabilecek minimum puan 45, maksimum puan 225 'tir. Bu araştırmada Saldırganlık ölçeğinin güvenirliği Cronbach’s Alpha=0,823 olarak yüksek bulunmuştur.

\section{Verilerin istatistiksel analizi}

Araştırmada elde edilen veriler SPSS 22.0 programı kullanılarak analiz edilmiştir. Verilerin değerlendirilmesinde tanımlayıcı istatistiksel yöntemleri olarak sayı, yüzde, ortalama, standart sapma uygulanmıştır. Yapılan normallik testine göre verilerin analizinde, iki gurubun ortalamaları arasındaki farkın anlamlı olup olmadığını incelemek için T-Testi, ikiden fazla bağımsız değişkenler ile bağımlı değişkenler ortalamaları arasındaki farkın tespiti için ANOVA testi kullanılmıştır. İki bağımsız grup arasında niceliksel sürekli verilerin karşılaştırılmasında t-testi, sürekli değişkenleri arasında ise pearson korelasyon uygulanmıştır.

\section{Bulgular ve Tartışma}

$\mathrm{Bu}$ bölümde, beden eğitimi ve spor öğretmenleri ile diğer öğretmenlerin vermiş oldukları cevaplar neticesinde ölçekler yoluyla toplanan verilerden, elde edilen bulgular yer almaktadır. Elde edilen bulgulara dayalı olarak açıklama ve yorumlar yapılmıştır. 
Tablo 1: Beden Eğitimi ve Spor Öğretmenleri ile Diğer Öğretmenlerin Tanımlayıcı Özelliklerin Dağılımı

\begin{tabular}{|c|c|c|c|c|c|}
\hline & & \multicolumn{2}{|c|}{ Beden Eğitimi } & \multicolumn{2}{|c|}{ Diğer Öğretmenler } \\
\hline & & $\mathbf{n}$ & $\%$ & $\mathbf{n}$ & $\%$ \\
\hline \multirow{2}{*}{ Cinsiyet } & Kadın & 41 & $\% 26,3$ & 114 & $\% 52,8$ \\
\hline & Erkek & 115 & $\% 73,7$ & 102 & $\% 47,2$ \\
\hline \multirow{2}{*}{ Yaş } & 30 ve Alt1 & 78 & $\% 50,0$ & 105 & $\% 48,6$ \\
\hline & 30 Üzeri & 78 & $\% 50,0$ & 111 & $\% 52,4$ \\
\hline \multirow{2}{*}{ Medeni Durum } & Evli & 73 & $\% 46,8$ & 133 & $\% 61,6$ \\
\hline & Bekar & 83 & $\% 53,2$ & 83 & $\% 38,4$ \\
\hline \multirow{2}{*}{ Öğrenim Durumu } & Üniversite & 139 & $\% 89,1$ & 191 & $\% 88,4$ \\
\hline & Yüksek Lisans & 17 & $\% 10,9$ & 25 & $\% 11,6$ \\
\hline \multirow{2}{*}{ Aylık Ortalama Gelir } & $3001-4000 \mathrm{TL}$ & 143 & $\% 91,7$ & 212 & $\% 98,1$ \\
\hline & $4001-5000 \mathrm{TL}$ & 13 & $\% 8,3$ & 4 & $\% 1,9$ \\
\hline \multirow{2}{*}{ Çalışılan Okul } & İlköğretim & 79 & $\% 50,6$ & 124 & $\% 57,4$ \\
\hline & Lise & 77 & $\% 49,4$ & 92 & $\% 42,6$ \\
\hline \multirow{4}{*}{ Öğretmenlik Tecrübesi } & 2 Yildan Az & 46 & $\% 29,5$ & 32 & $\% 14,8$ \\
\hline & 3-5 Y11 & 50 & $\% 32,1$ & 65 & $\% 30,1$ \\
\hline & 6-10 Yil & 34 & $\% 21,8$ & 70 & $\% 32,4$ \\
\hline & 10 Y1l Üzeri & 26 & $\% 16,7$ & 49 & $\% 22,7$ \\
\hline \multirow{2}{*}{ İdari Görev Durumu } & Evet & 17 & $\% 10,9$ & 13 & $\% 6,0$ \\
\hline & Hayır & 139 & $\% 89,1$ & 203 & $\% 94,0$ \\
\hline
\end{tabular}

Tablo 1'de beden eğitimi ve spor öğretmenleri cinsiyete göre 41'i $(\% 26,3)$ kadın, 115'i $(\% 73,7)$ erkek olarak dağılmaktadır. Diğer branş öğretmenler ise cinsiyete göre 114 'ü $(\% 52,8)$ kadın, 102'si $(\% 47,2)$ erkek olarak dağılmaktadır.

Beden eğitimi ve spor öğretmenleri yaşa göre 78 'i $(\% 50,0) 30$ ve altı, 78'i $(\% 50,0) 30$ üzeri olarak dağılmaktadır. Diğer branş öğretmenler ise yaşa göre 105 'i $(\% 48,6) 30$ ve altı, $111^{\prime} \mathrm{i}(\% 52,4)$ 30 üzeri olarak dağılmaktadır.

Beden eğitimi ve spor öğretmenleri medeni duruma göre 73’ü $(\% 46,8)$ evli, 83'ü $(\% 53,2)$ bekar olarak dağılmaktadır. Diğer branş öğretmenler ise medeni duruma göre 133' ü $(\% 61,6)$ evli, 83 'ü $(\% 38,4)$ bekar olarak dağılmaktadır.

Beden eğitimi ve spor öğretmenleri öğrenim durumuna göre 139'u $(\% 89,1)$ üniversite, 17 'si $(\% 10,9)$ yüksek lisans olarak dağılmaktadır. Diğer branş öğretmenler ise öğrenim durumuna göre 191'i $(\% 88,4)$ üniversite, 25'i $(\% 11,6)$ yüksek lisans olarak dağılmaktadır.

Beden eğitimi ve spor öğretmenleri aylık ortalama gelir durumuna göre 143'ü $(\% 91,7)$ 3001-4000 TL, 13'ü (\%8,3) 4001-5000 TL olarak dağılmaktadır. Diğer branş öğretmenler ise aylık ortalama gelir durumuna göre 212'si $(\% 98,1)$ 3001-4000 TL, 4'ü $(\% 1,9)$ 4001-5000 TL olarak dağılmaktadır.

Beden eğitimi ve spor öğretmenleri çalışlan okul durumuna göre 79’u $(\% 50,6)$ ilköğretim, 77 'si $(\% 49,4)$ lise olarak dağılmaktadır. Diğer branş öğretmenler ise çalışılan okul durumuna göre $124(\% 57,4)$ ilköğretim, 92'si $(\% 42,6)$ lise olarak dağılmaktadır.

Beden eğitimi ve spor öğretmenleri öğretmenlik tecrübesine göre 46's1 $(\% 29,5) 2$ Y1ldan Az, 50'si (\%32,1) 3-5 yıl, 34'ü (\%21,8) 6-10 yıl, 26's1 (\%16,7) 10 y1l üzeri olarak dağılmaktadır. Diğer branş öğretmenler ise öğretmenlik tecrübesine göre 32'si $(\% 14,8) 2$ y1ldan az, 65'i $(\% 30,1)$ 3-5 yıl, 70’i (\%32,4) 6-10 yıl, 49’u (\%22,7) 10 yıl üzeri olarak dağılmaktadır. 
Beden eğitimi ve spor öğretmenleri idari görev durumuna göre 17'si $(\% 10,9)$ evet, 139’u $(\% 89,1)$ hayır olarak dağılmaktadır. Diğer branş öğretmenler ise idari görev durumuna göre 13'ü $(\% 6,0)$ evet, 203'ü $(\% 94,0)$ hayır olarak dağılmaktadır.

Tablo 2: Sosyal Görünüş Kaygısı ve Saldırganlık Puanlarının Öğretmenlik Alanı Göre Farklılaşma Durumu

\begin{tabular}{|c|c|c|c|c|c|c|c|c|c|}
\hline \multirow[t]{2}{*}{ Gruplar } & & \multicolumn{2}{|c|}{$\begin{array}{l}\text { Beden Eğitimi } \\
\quad(n=156)\end{array}$} & \multicolumn{2}{|c|}{$\begin{array}{c}\text { Diğer Öğretmenler } \\
(\mathbf{n = 2 1 6 )}\end{array}$} & \multirow[t]{2}{*}{$\mathbf{t}$} & \multirow[t]{2}{*}{ sd } & \multirow[t]{2}{*}{$\mathbf{p}$} & \multirow{2}{*}{$\begin{array}{l}\text { İki Grup } \\
\text { Puan Ort }\end{array}$} \\
\hline & & Ort & Ss & Ort & Ss & & & & \\
\hline $\begin{array}{l}\text { Sosyal } \\
\text { Kaygis1 }\end{array}$ & Görünüş & 30,359 & 11,818 & 30,852 & 10,169 & $-0,431$ & 370 & 0,667 & 30,60 \\
\hline Saldırganlık & & 92,410 & 13,819 & 88,148 & 12,288 & 3,132 & 370 & 0,002 & 90,279 \\
\hline
\end{tabular}

Bağımsız Gruplar T-Testi

Tablo 2'de öğretmenlerin öğretmenlik alanı göre saldırganlık puanları anlamlı farklılık göstermektedir $\left(\mathrm{t}_{(370)}=3.132 ; \mathrm{p}=0.002<0,05\right)$. Her iki grubun saldırganlık düzeyi puan ortalamaları aritmetik ortalamanın altında olduğu için düşük saldırganlık düzeyini göstermektedir. Beden eğitimi ve spor öğretmenlerinin saldırganlı puanları $(\overline{\mathrm{x}}=92,410)$, diğer branş öğretmenlerin saldırganlık puanlarından $(\overline{\mathrm{x}}=88,148)$ yüksek bulunmuştur. Bu durumun beden eğitimi ve spor öğretmenlerinin öğrencilerle iletişimde sadece ders içerisindeki etkileşimlerinin yanında, okul içerisindeki boş zamanlarda da sürekli etkileşimde oldukları, haliyle öğrencilerin bu etkileşimi suiistimal etmelerinden kaynaklı beden eğitimi ve spor öğretmenleri öğrencilere karşı tutumlarında sabırsız davranabildikleri düşünülmektedir.

Öğretmenlerin sosyal görünüş kaygısı puanları öğretmenlik alanı değişkenine göre anlamlı farkl11ık göstermemektedir $(\mathrm{p}>0,05)$.

Tablo 3: Sosyal Görünüss Kaygısı ve Saldırganlık Puanları Arasında Korelasyon Analizi Sosyal Görünüş Kaygısı

\begin{tabular}{lll} 
& & Sosyal Görünüş Kaygısı \\
\hline \multirow{2}{*}{ Saldırganlık } & $\mathrm{r}$ & $0,413^{* *}$ \\
& $\mathrm{p}$ & 0,000 \\
\hline
\end{tabular}

$*<0,05 ; * *<0,01$

Tablo 3'de sosyal görünüş kaygısı, saldırganlık, arasında korelasyon analizleri incelendiğinde; Saldırganlık ile sosyal görünüş kaygısı arasında $r=0.413$ pozitif $(\mathrm{p}=0,000<0.05)$ ilişki bulunmuştur. 
Tablo 4: Beden Eğitimi ve Spor Öğretmenleri ve Diğer Öğretmenlerde Sosyal Görünüş Kaygıs1, Saldırganlık Puanlarının Tanımlayıcı Özelliklere Göre Karșılaştırılması

\begin{tabular}{|c|c|c|c|c|c|c|c|c|}
\hline \multirow{6}{*}{$\begin{array}{l}\text { Demografik } \\
\text { Özellikler } \\
\text { Cinsiyet } \\
\text { Kadın } \\
\text { Erkek } \\
\mathrm{t}=\end{array}$} & \multicolumn{3}{|c|}{ Beden Eğitimi Öğretmenleri } & \multicolumn{5}{|c|}{ Diğer Öğretmenler } \\
\hline & $\bar{n}$ & $\begin{array}{c}\text { Sosyal } \\
\text { Görünüsş } \\
\text { Kaygısı }\end{array}$ & Saldırganlık & & $\mathbf{n}$ & $\begin{array}{c}\text { Sosyal } \\
\text { Görünüş } \\
\text { KaygISI }\end{array}$ & Saldırga & llık \\
\hline & & Ort \pm SS & Ort \pm SS & P.Ort & & $\mathbf{O r t} \pm \mathbf{S S}$ & Ort $\pm \mathbf{S S}$ & P.Ort \\
\hline & 41 & $33,390 \pm 15,161$ & $95,610 \pm 16,769$ & & 114 & $29,860 \pm 9,046$ & $85,947 \pm 11,358$ & 88277 \\
\hline & 115 & $29,278 \pm 10,236$ & $91,270 \pm 12,490$ & 93,44 & 102 & $31,961 \pm 11,234$ & $90,608 \pm 12,865$ & 88,217 \\
\hline & & 1,930 & 1,738 & & & $-1,521$ & $-2,828$ & \\
\hline$p=$ & & 0,113 & 0,136 & & & 0,135 & 0,005 & \\
\hline Yaş & & Ort \pm SS & Ort \pm SS & P.Ort & & Ort \pm SS & Ort $\pm \mathbf{S S}$ & P.O \\
\hline 30 ve Alt 1 & 78 & $32,295 \pm 13,376$ & 14,821 & & 105 & 9,297 & 2,681 & \\
\hline 30 Üzeri & 78 & $28,423 \pm 9,729$ & $89,333 \pm 12,065$ & 92,41 & 111 & $31,126 \pm 10,965$ & $87,559 \pm 11,931$ & 88,16 \\
\hline$t=$ & & 2,067 & 2,844 & & & $-0,407$ & 0,724 & \\
\hline $\mathrm{p}=$ & & 0,041 & 0,005 & & & 0,685 & 0,470 & \\
\hline $\begin{array}{l}\text { Medeni } \\
\text { Durum }\end{array}$ & & Ort \pm SS & Ort \pm SS & P.Ort & & Ort \pm SS & Ort \pm SS & P.Ort \\
\hline Evli & 73 & & & & 133 & 30,985 & $87,323 \pm 12$ & \\
\hline Bekar & 83 & $30,145 \pm 12,002$ & $93,699 \pm 12,790$ & 92,322 & 83 & $30,639 \pm 9,248$ & $89,470 \pm 12,108$ & 88,390 \\
\hline$t=$ & & 0,241 & $-1,244$ & & & 0,243 & $-1,25$ & \\
\hline$p=$ & & 0,810 & 0,215 & & & 0,808 & 0,212 & \\
\hline $\begin{array}{l}\text { Çalışılan } \\
\text { Okul }\end{array}$ & & Ort \pm SS & Ort \pm SS & P.Ort & & Ort \pm SS & Ort \pm SS & P.Ort \\
\hline İlköğretim & 79 & & & & 124 & $29,476 \pm 8$ & $88,040 \pm 1$ & \\
\hline Lise & 77 & $31,792 \pm 12,307$ & $94,299 \pm 14,733$ & 92,434 & 92 & $32,707 \pm 1$ & $88,294 \pm 13,115$ & 88,16 \\
\hline$t=$ & & $-1,501$ & $-1,695$ & & & $-2,333$ & $-0,149$ & \\
\hline $\mathrm{p}=$ & & 0,135 & 0,092 & & & $\mathbf{0 , 0 2 7}$ & 0,881 & \\
\hline $\begin{array}{l}\text { Öğretmenlik } \\
\text { Tecrübesi }\end{array}$ & & Ort \pm SS & Ort \pm SS & P.Ort & & Ort \pm SS & Ort \pm SS & P.Ort \\
\hline $\mathrm{an} \mathrm{Az}$ & 46 & & & & 32 & & & \\
\hline 3-5 Yil & 50 & $28,620 \pm 11,547$ & $91,080 \pm 13,437$ & 01080 & 65 & $31,246 \pm 9,956$ & $87,769 \pm 11,160$ & \\
\hline 6-10 Y1l & 34 & $28,118 \pm 9,387$ & $89,206 \pm 12,579$ & 91,909 & 70 & $29,629 \pm 10,144$ & $88,343 \pm 12,339$ & 80,32 \\
\hline 10 Y1l Üzeri & 26 & $30,577 \pm 9,758$ & $90,192 \pm 12,100$ & & 49 & $32,918 \pm 12,362$ & $87,143 \pm 13,452$ & \\
\hline $\mathrm{F}=$ & & 2,102 & 3,178 & & & 1,220 & 0,3 & \\
\hline $\begin{array}{l}\mathrm{p}= \\
\text { PostHoc }=\end{array}$ & & 0,102 & $\begin{array}{l}\mathbf{0 , 0 2 6} \\
1>2, \quad 1>3, \\
1>4(p<0.05)\end{array}$ & & & 0,303 & 0,765 & \\
\hline $\begin{array}{l}\text { İdari Görev } \\
\text { Durumu }\end{array}$ & & Ort \pm SS & Ort \pm SS & P.Ort & & Ort \pm SS & Ort \pm SS & P.Ort \\
\hline Evet & 17 & $36,000 \pm 14,921$ & $96,059 \pm 16,887$ & & 13 & $31,692 \pm 8,128$ & $89,231 \pm 12,524$ & \\
\hline Hayır & 139 & $29,669 \pm 11,255$ & $91,964 \pm 13,401$ & 94,011 & 203 & $30,798 \pm 10,300$ & $88,079 \pm 12,301$ & 88,655 \\
\hline$t=$ & & 2,108 & 1,154 & & & 0,307 & 0,327 & \\
\hline$p=$ & & $\mathbf{0 , 0 3 7}$ & 0,250 & & & 0,759 & 0,744 & \\
\hline
\end{tabular}

Tablo 4'de beden eğitimi ve spor öğretmenleri sosyal görünüş kaygısı, saldırganlık puanları cinsiyet değişkenine göre anlamlı farklılık göstermemektedir ( $>0.05)$. Elde ettiğimiz bu sonuç ile Hyde'ın (2005) cinsiyet benzerlikleri hipotezi ile parelellik göstermektedir. Hyde (2005) erkekler ve kadınların bütün psikolojik değişkenlerde olmasa da çoğunlukla cinsiyetler arasında farklılaşma olmadığını ileri sürmektedir. Türkiye örnekleminde incelenen çalışmalara bakıldığında elde edilen sonuçlar ile paralellik gösteren çok miktarda çalışmanın olduğunu söyleyebiliriz (Ben, 2017; Göksel, Caz, Yazıcı ve Zorba, 2018; Gül, 2016; Kalemoglu Varol, Erbas, Unlu, 2014; Şahin, Barut ve Ersanli, 2013; Şahin, Tekeli, 2017). 
Diğer öğretmenlerin sosyal görünüş kaygısı puanlarında cinsiyet değişkenine göre anlamlı farklılık göstermezken $(\mathrm{p}>0.05)$, saldırganlık puanlarında anlamlı farklılık göstermektedir $(\mathrm{p}<0.05)$. Beden eğitimi ve spor ögretmenlerinde kadınların saldırganlık puanları $(\overline{\mathrm{x}}=95,610)$, erkeklerin saldırganlık puanlarından ( $\overline{\mathrm{x}}=91,270)$ yüksek bulunmuştur $(\mathrm{t}=-1,738 ; \mathrm{p}=0.05>0,136)$. Diğer öğretmenlerde ise kadınların saldırganlık puanları $(\overline{\mathrm{x}}=85,947)$, erkeklerin saldırganlık puanlarından $(\overline{\mathrm{x}}=90,608)$ düşük bulunmuştur $(\mathrm{t}=-2,828 ; \mathrm{p}=0.005<0.05)$. Bu sonuç Eroğlu'nun (2009) yapmış olduğu çalışmada saldırganlık alt boyutlarının çoğunda erkek öğrencilerin kadın öğrencilerden daha yüksek saldırganlık puanlarına sahip olduğu çalışmamızla paralellik göstermektedir.

Beden eğitimi ve spor öğretmenlerinde yaş 30 ve altı olanların sosyal görünüş kaygısı puanları ( $\overline{\mathrm{x}}=32,295)$, yaş 30 üzeri olanların sosyal görünüş kaygısı puanlarından $(\overline{\mathrm{x}}=28,423)$ yüksek bulunmuştur $(\mathrm{t}=2,067 ; \mathrm{p}=0.041<0.05)$. Yaş 30 ve altı olanların saldırganlık puanları $(\overline{\mathrm{x}}=95,487)$, yaş 30 üzeri olanların saldırganlık puanlarından $(\overline{\mathrm{x}}=89,333)$ yüksek bulunmuştur $(\mathrm{t}=2,844$; $\mathrm{p}=0.005<0.05$ ). Diğer öğretmenlerde ise yaş 30 ve altı olanların sosyal görünüş kaygısı puanları $(\overline{\mathrm{x}}=30,562)$, yaş 30 üzeri olanların sosyal görünüş kaygısı puanlarından $(\overline{\mathrm{x}}=31,126)$ düşük bulunmuştur $(\mathrm{t}=-0,407 ; \mathrm{p}=0.05>.685)$. Yaş 30 ve altı olanların saldırganlık puanları $(\overline{\mathrm{x}}=88,78)$, yaş 30 üzeri olanların saldırganlık puanlarından $(\overline{\mathrm{x}}=87,559)$ yüksek bulunmuştur $(\mathrm{t}=0,724$; $\mathrm{p}=0.05>0,470$ ). Çalışmamıza paralel olarak Telli ve Ünal'ın yapmış oldukları çalışmada üniversitede okuyan öğrencilerin sosyo-demografik yapılarına göre sosyal görünüş kaygılarına bakıldığında üniversite okuyan öğrencilerinin sosyal görünüş kaygılarının öğrencilerin yaş ve sınıf düzeylerine göre arasında anlamlı bir farklılık bulunmuştur. Bu durum sosyal görünüş kaygısını yaş ile paralel olarak yaş arttıkça sosyal görünüş kaygıların azaldığını, saldırganlık puanlarınında parelel olarak yaş arttıkça azaldığını söyleyebiliriz.

Beden eğitimi ve spor öğretmenleri ve diğer öğretmenlerin sosyal görünüş kaygısı, saldırganlık puanları medeni durum değişkenine göre anlamlı farklılık göstermemektedir( $\mathrm{p}>0.05)$. Çalışma ile parelel olarak Yorulmaz ve Kurutçu'nun (2019) yapmış oldukları çalışmada medeni durum ve sosyal görünüş kaygısı arasında anlamlı bir fark bulunmamıştır.

Beden eğitimi ve spor öğretmenlerinde sosyal görünüş kaygısı, saldırganlık puanları çalışılan okul değişkenine göre anlamlı farklılık göstermemektedir( $\mathrm{p}>0.05)$. Diğer öğretmenlerde ilköğretim okulunda görev yapanların sosyal görünüş kaygısı puanları $(\bar{x}=29,476)$, lisede görev yapanların sosyal görünüş kaygısı puanlarından $(\bar{x}=32,707)$ düşük bulunmuştur $(t=-2,333$; $\mathrm{p}=0.027<0.05)$. Alemdağ ve Öncü'nün $(2015)$ yapmış olduğu çalışmada ise 1 . ve 2 . sınıfta okuyan üniversite öğrencilerin 3. ve 4. Sinıfta okuyan üniversite öğrencilerine göre sosyal görünüş kaygılarının daha yüksek çıktığı bulunmuştur. Bu durum lise öğrencilerinin ergenliğe girmeleriyle beraber, öğretmenlerini rol model alma durumları, öğretmenlerin ise bunu görmezden gelmeyerek sosyal görünüşlerine daha dikkat ettikleri düşünülebilir. Diğer öğretmenlerin saldırganlık puanları çalış1lan okul değişkenine göre anlamlı farklılık göstermemektedir( $\mathrm{p}>0.05)$.

Beden eğitimi ve spor öğretmenlerin saldırganlık puanları öğretmenlik tecrübesi değişkenine göre anlamlı farklılık göstermektedir $(\mathrm{F}=3,178 ; \mathrm{p}=0.026<0.05)$. Farkın nedeni Öğretmenlik tecrübesi 2 yıldan az olanların saldırganlık puanlarının öğretmenlik tecrübesi 3-5 yıl olanların saldırganlık puanlarından yüksek olmasıdır $(\mathrm{p}<0.05)$. Öğretmenlik tecrübesi 2 yıldan az olanların saldırganlık puanlarının öğretmenlik tecrübesi 6-10 yıl olanların saldırganlık puanlarından yüksek olmasıdır $(\mathrm{p}<0.05)$. Öğretmenlik tecrübesi 2 y1ldan az olanların saldırganlık puanlarının öğretmenlik tecrübesi 10 yıl üzeri olanların saldırganlık puanlarından yüksek olmasıdır $(p<0.05)$. Yine yaş ile ilişili olarak yaş artıkça saldırganlık durumlarının azaldığı, yaş azaldığında ise salırganlık durumlarının arttığını söyleyebiliriz. Diğer öğretmenlerin saldırganlık puanlarının öğretmenlik tecrübesi değişkenine göre ise anlamlı farklılık göstermemektedir( $\mathrm{p}>0.05)$.Beden eğitimi ve spor öğretmenleri ve diğer öğretmenlerin sosyal görünüş kaygısı puanları öğretmenlik tecrübesi değişkenine göre anlamlı farkl1lık göstermemektedir ( $>0.05)$. 
Beden eğitimi ve spor öğretmenlerinde idari görevi olanların sosyal görünüş kaygısı puanları $(\bar{x}=36,000)$, idari görevi olmayanların sosyal görünüş kaygısı puanlarından $(\bar{x}=29,669)$ yüksek bulunmuştur $(\mathrm{t}=2,108 ; \mathrm{p}=0.037<0.05)$. Başka bir çalışmada Sunay (1997)'de Ankara ilinin bazı ilçelerinde idareci olan ve idareci olmayı talep eden beden eğitimi ve spor öğretmelerinin yüksek çıktığı buda idarecilik yapmak isteyen beden eğitimi ve spor öğretmenlerinin daha istekli olmaları sosyal görünüş kaygı puanlarını artırabileceği düşünülmektedir. Diğer öğretmenlerde ise sosyal görünüş kaygısı, saldırganlık puanları idari görev durumu değişkenine göre anlamlı farklılık göstermemektedir ( $>00.05)$. Beden eğitimi ve spor öğretmenleri ve diğer öğretmenlerin saldırganlık puanları idari görev durumu değişkenine göre anlamlı farklılık göstermemektedir( $\mathrm{p}>0.05)$.

Her iki grubun Saldırganlık düzeyi puan ortalamalarına bakıldığında ise puanların aritmetik ortalamanın altında olduğu için düşük saldırganlık düzeyi gösterdiği görülmüştür.

\section{Sonuç ve öneriler}

Beden eğitimi ve spor öğretmenlerin sosyal görünüş kaygısı ve saldırganlık envanteri ölçeğinde yaş, öğretmenlik tecrübesi ve idari görev durumu değişkenlerine göre anlamlı farklılık görülürken cinsiyet, medeni durum ve çalışılan okul değişkenlerine göre anlamlı farklılık olmadığı görülmüştür. Diğer branş öğretmenlerin ise cinsiyet ve çalış1lan okul değişkenlerine göre anlamlı farkl1lık görülürken yaş, medeni durum, öğretmenlik tecrübesi ve idari görev durumu değişkenlerine göre anlamlı farklılık olmadığı görülmüştür. Beden eğitimi ve spor öğretmenlerinin saldırganlık puanları diğer branş öğretmenlerinin saldırganlık puanlarından yüksek olduğu bulunmuştur. Ayrıca sosyal görünüş kaygısı ve saldırganlık tutumu arasında pozitif yönde anlamlı ilişki bulunmuştur.

Örneklem gurubunun Doğu Anadolu ve Güney Doğu Anadolu bölgesinden seçilmesi sosyal yaşam içerisindeki uyumlarında bir takım zorluklarıda beraberinde getirebilmektedir. Bölge, şehir, okul vb. ortamından kaynaklanabilecek zorluklar kaygı, stres ve saldırganlık durumlarınıda direkt etkileyebildiğini görmekteyiz. Uygulayıcılara yönelik özellikle okul ortamı ve sosyal yaşam imkanlarının kısıtlılıklarında kültür, sanat ve spor gibi sosyal faaliyetlerde bulunmaları önerilmektedir.

Beden eğitimi ve spor öğretmenleri ile diğer öğretmenler olarak örneklemi belirlenen bu araştırma; farklı bölgeler, farklı şehirler, farklı yaş gurupları, farklı meslek gurupları, farklı devlet yada özel okullar ilede yürütülebilir. İdari görev durumuna göre gruplar daha homojen olacak şekilde örneklem grubunun seçilmesi daha farklı sonuçlar ortaya koyabileceği düşünülmektedir.

Beden eğitimi ve spor öğretmenleri ile diğer öğretmenlerin sosyal görünüş kaygısı ve saldırganlık tutumlarında yaşanan olumsuz tutumların görüşme ve gözlem teknikleriyle sebepleri detaylı olarak ele alınarak nitel çalışmalar gerçekleştirilebilir.

\section{Kaynakça}

Alemdağ, S., \& Öncü, E. (2015). Öğretmen adaylarının fiziksel aktiviteye katılım ve sosyal görünüş kaygılarının incelenmesi. International Journal of Science Culture and Sport (IntJSCS). 3, 287-300. https://doi.org/10.14486/IJSCS29

Ben, S. (2017). İstanbul'da yaşayan üniversite öğrencilerinin sosyal anksiyete düzeyleri ile beden algısı olumsuz değerlendirilme korkusu sosyal görünüş kaygısı arasındaki ilişkinin incelenmesi (Yüksek Lisans Tezi). Yükseköğretim Kurulu Ulusal Tez Merkezi'nden edinilmiştir (Tez No. 460423). https://doi.org/10.34087/cbusbed.600130

Çınar, H., \& Keskin, N. (2015). Öğrencilerin Sosyal Görünüş Kaygısının Öğrenim Yeri Tercihlerine Etkisi. Electronic Journal of Vocational Colleges, 14(1). 457-465. https://doi.org/10.17339/ejovoc.53718 
Doğan, O. (2005). Spor psikolojisi. Adana: Nobel Kitapevi.

Doğan, T. (2010). Sosyal görünüş kaygısı ölçeğinin (sgkö) Türkçe uyarlaması: geçerlik ve güvenirlik çalışması. Hacettepe Üniversitesi Eğitim Fakültesi Dergisi, 39(1), 151-159. https://doi.org/10.17679/inuefd.302675

Eroğlu, S. E. (2009). Saldırganlık davranışının boyutları ve ilişsili olduğu faktörler: lise ve üniversite ögrencileri üzerine karşılaştırmalı bir çalışma (Doktora Tezi). Yükseköğretim Kurulu Ulusal Tez Merkezi'nden edinilmiştir (Tez No. 235272). https://doi.org/10.18505/cuifd.48040

Eroğlu, S. Y., \& Acet, M. (2017). İşitme engelli öğrencilerin spor yapma değişkenine göre sosyal görünüş kaygısı ile yaşam kalitesi düzeylerinin incelenmesi. Türkiye Klinikleri Spor Bilimler Dergisii, 6(2), 68-75. https://doi.org/10.5336/sportsci.2016-54033

Göksel, A. G., Caz, Ç., Yazıcı, Ö. F., \& Zorba, E. (2018). Spor hizmeti alan bireylerin sosyal görünüş kaygısı ve öznel mutluluklarının incelenmesi. Gaziantep Üniversitesi Spor Bilimleri Dergisi, 3(3), 88- 101. https://doi.org/10.31680/gaunjss.434184

Gül, E. (2016). Ergenlerde sosyal görünüs kaygısı ve sosyal karşılaştırmanın fonksiyonel olmayan tutum ve bilişsel çarpıtmalarla ilişkisi (Yüksek Lisans Tezi). Yükseköğretim Kurulu Ulusal Tez Merkezi'nden edinilmiştir (Tez No. 441626). https://doi.org/10.12780/uusbd129

Gümüşay, A. (2019). Beden eğitimi ve sporda istihdam edilebilme. Ankara: Nobel Akademik Yayıncilik.

Hart, T. A., Flora, D. B., Palyo, S. A., Fresco, D. M., Holle, C., \& Heimberg, R. C. (2008). Development and examination of the social appearance anxiety scale. Assessment, 15(1), 48-59. https://doi.org/10.1177/1073191107306673

Hyde, J. S. (2005). The gender similarities hypothesis. American psychologist, 60(6), 581-592. https://doi.org/10.1037/0003-066x.60.6.581

Kalemoğlu, Y., Erbaş, M. K., \& Ünlü, H. (2014). Ergenlerin sosyal görünüş kaygıları ile beden eğitimi dersine yönelik tutumları arasındaki ilişki. Niğde Üniversitesi Beden Eğitimi ve Spor Bilimleri Dergisi, 8(1), 121-130. https://doi.org/10.1501/sporm_0000000359

Murathan T., \& Murathan F. (2019). Spor sektöründe blok zinciri uygulamaları, Gaziantep Üniversitesi Spor Bilimleri Dergisi, 4(1), 64-74. https://doi.org/10.31680/gaunjss.484614

Sunay, Y. (1997). İlk ve orta dereceli okullarda beden eğitimi öğretmenlerinin okul müdürü olmasının engelleri. Gazi Beden Eğitimi ve Spor Bilimleri Dergisi,2(2), 39-55. https://doi.org/10.1501/sporm_0000000139

Şahin, E., Barut, Y., \& Ersanli, E. (2013). Sociodemographic variables in relation to social appearance anxiety in adolescents. Online Submission, 15(1), 56-63.

Taşkaya, S. M. (2012). Nitelikli bir öğretmende bulunması gereken özelliklerin öğretmen adaylarının görüşlerine göre incelenmesi. Sosyal Bilimler Enstitüsü Dergisi, 33, 283-298. https://doi.org/10.12780/uusbd185

Tekeli, Ş. C. (2017). Beden ĕgitimi ve spor öğretmeni adaylart ile diğer ögretmen adaylarının sosyal görünüş kaygısı ve akademik öz-yeterlik düzeylerinin karşılaştırllması (Yüksek Lisans Tezi). Yükseköğretim Kurulu Ulusal Tez Merkezi'nden edinilmiştir (Tez No. 470976). https://doi.org/10.32706/tusbid.419468

Telli, E. \& Ünal, Z. (2016). Üniversite öğrencilerinin sosyo-demografik özelliklerine göre sosyal görünüş kaygısı. Mehmet Akif Ersoy Üniversitesi Sosyal Bilimler Enstitüsü Dergisi, 8(15) 134-146. https://doi.org/10.20875/sb.98440 
Beden Eğitimi ve Spor Öğretmenleri ile Diğer Öğretmenlerin Sosyal Görünüş Kaygisi ve.... 1023

Tiryaki, Ş. (1997). Spor yapan bireylerin saldirganlık düzeylerinin belirlenmesi: taklm ve bireysel sporlar açısından bir inceleme. Uluslararası Spor Psikolojisi Sempozyumu, (s. 10-12). Mersin: Ekim. https://doi.org/10.17719/jisr.2017.1671

Tiryaki, Ş. (2000). Spor psikolojisi. Ankara: Eylül Kitap ve Yayınevi.

Tuzgöl, M. (1998). Anne-baba tutumları farklı lise öğrencilerinin saldırganlık düzeylerinin çeşitli değişkenler açısından incelenmesi (Yüksek Lisans Tezi). Yükseköğretim Kurulu Ulusal Tez Merkezi'nden edinilmiştir (Tez No. 73627). https://doi.org/10.17556/erziefd.331083

Yorulmaz, M., \& Kurutçu, Ş. (2019). Vücut algıs1 ve sosyal görünüş kaygısı ilişkisinin incelenmesi. Avrasya Sosyal ve Ekonomi Araştırmalart Dergisi,6(2), 195-208. https://doi.org/10.17681/hsp.429806 